\title{
Evaluation and land use planning process of a high population growth rate municipality: Los Cabos, Mexico
}

\author{
O. Arizpe ${ }^{1}$, J. Fermán ${ }^{2}$, R. Rivera ${ }^{1}$, J. Ramírez $^{2} \&$ R. Rodríguez ${ }^{1}$ \\ ${ }^{1}$ Universidad Autónoma de Baja California Sur. La Paz, México \\ ${ }^{2}$ Universidad Autónoma de Baja California Ensenada, México
}

\begin{abstract}
The high productivity, diversity and social-economic importance of coastal systems and their components present a very complex scheme that requires a detailed knowledge of the characteristics of the environment and socialeconomic factors. This has been designated as high priority in the Municipality of Los Cabos, Mexico, where inadequate development plans, caused by a very high rate of economic and population growth ( $9 \%$ per year), have turned it into an extremely vulnerable area with high pressure from the irregular growth of tourists facilities. The purpose of this study was, precisely, to develop a model of ecological ordinance or land use planning in general for the region. This model could integrate other processes of environmental planning that are currently in operation at municipal level, such as those for regional and marine planning in the Gulf of California. A characterization of all environmental, social and economic components of the municipality was carried out. Eighty one environmental units, or micro regions, were identified and mapped out using a scale of 1:50 000 on the basis of sub river basins, physiography and vegetation, integrated with all the data bases available in a Geographic Information System (GIS) of the whole Municipality. A diagnosis and prospective analysis of different scenarios were also developed, using fragility, pressure and vulnerability indicators. Finally, it was realized that the Los Cabos region needs to change its economic development approach, proposing a general model of ecological ordinance with specific actions and criteria of land use for each microregion.
\end{abstract}

Keywords: prospective analysis, Los Cabos, land use planning. 


\section{Introduction}

The high productivity, diversity and great socio-economic importance of coastal systems have high potential for economic development. A scientific foundation is needed for adequate management of such areas. A scientific foundation preserves natural resources in an area, identifies new potential resources, and provides the tools to develop suitable management policies for sustainable development of the coastal system as a whole. Ecological Territorial Ordering is a tool to create a diagnosis, based on biophysical and socio-economic variables, arranged in a combination of administrative units (municipalities) and Enviromental Units for improved management (León et al. [1]).

The municipality of Los Cabos is part of the Gulf of California, and is located in the south of the Baja California Peninsula. It is an area of great cultural and historical value, impressive scenery and high tourism potential. All this contributes to the zone's large capacity to generate important economical benefits, at both regional and national levels. Tourism in Los Cabos is increasing. It is an area of luxury tourist infrastructure, which combined with it's natural beauty generates a wide range of tourism activities. In recent years, it has become the region with the highest population growth rate in Mexico (9.2\% per year, INEGI [2]). This is due primarily to the economic growth generated by the tourism sector, which has resulted in a great increase in the demand for services and infrastructure (CEI [3]) and inmigration.

The main economic potential of the area is located in the housing and recreational sectors.

The problems generated by the accelerated and disorderly growth include conflicts over land ownership, unplanned settlements in the maritime federal areas (especially in the Eastern Cape region), degradation of the coastline and water shortage related problems that have been increasing in the Municipality of Los Cabos and particularly in the Eastern Cape region.

A detailed evaluation is needed of the biophysical and socio-economic characteristics of the municipality, to generate management policies and sustainable development of productive activities, which would improve the quality of life of communities and the conservation of natural resources. This work proposes a model for land use in the municipality of Los Cabos, Mexico, developed from an assessment of environmental characteristics, a socioeconomic diagnosis and the suitability of the area. The proposed land use planning would allow a relocation of the land use, and a better planning of productive activities in the region.

\section{Methods}

Comprehensive and interdisciplinary methodologies, previously used in Mexico to make Ecological Orderings were used in this work. A technical study integrated the development of four stages: characterization, diagnosis, prognosis and proposal. The implementation of each of them has a clear purpose and a series of products, and each step is subject to the guidelines and mechanisms established by Mexican standards. 
Characterization The evaluation of the area began with the characterization of the municipality. It identified the study area and integrated environmental information to create zones on a 1/50 000 scale. The zonning established Environmental Units (EU), and define a framework for the analysis of the area from an ecological perspective. It was based on the hierarchical arrangement of three elements that were considered relevant to this process: surface hydrology, topography and vegetation. The resulting map fragmented the municipality into homogenous areas that correspond to unique environmental processes. These are named Enviromental Units.

Diagnosis This was to define which parameters of the established sectors were relevant in the region (tourism, agriculture and conservation) and to develop specific models for each of them. Workshops, involving peoplefrom each sector, were used to adjust proposed ratings in parameter indexes for each sector.

Prospective This phase consisted of calculating the composite indices of Pressure (IP), Fragility (IF), Vulnerability (IV) and the definition of environmental policies for each EU. The IP was composed of two components:

- Index of pressure suitability of the productive sectors and agricultural tourism (PSEC)

PSEC $=$ ITUR + IAP

ITUR $=$ Touristic parameter (Normalizad Value)

IAP $=$ Agricultural parameter (Normalized Value)

- $\quad$ Pressure by Population and Transformed Land Use Index (IPU)

- $\quad \mathrm{IPU}=\mathrm{IUS}+\mathrm{IPOB}$

IUS $=$ Transformed Land Use Index

IPOB $=$ Population Index

IF was defined as the equivalent index fitness maintenance [4]. The vulnerability index (IV) was the sum of IP and IF. This index spatially defined areas with greater demand for the natural resources of greatest vulnerability.

$\mathrm{IV}=\mathrm{IP}+\mathrm{IF}$

IP $=$ Pressure Index

$\mathrm{IF}=$ Fragility Index (Index of conservation suitability)

Environmental policies were established from the fragility, pressure and vulnerability values. According to Article III of the General Law of Ecological Balance and Environmental Protection (LGEEPA) (SEMARNAT [5]). the relevant policies were:

- Sustainable Use,

- Conservation and Preservation.

Proposal At this stage, the ecological ordering program was developed. It's an integration of 2 main elements: 1) Model of Ecological Ordering and 2) Environmental Strategies. To achieve this, Environmental Management Units (EMU) were identified through a rezonification of the area from the criteria of the parameters for each sector (the sectorial interactions, [4]). The indices were composed of fragility, vulnerability and pressure, environmental policies by EU and the Natural Protected Areas. Each EMU was assigned an environmental policy on the basis of environmental policies for Environmental Unit obtained at the pronostic stage, according to the proposed categories in Article III of the LGEEPA. 
Finally, guidelines and strategies were established for each ecological EMUspecifying authorized, prohibited or conditional land uses for each area.

\section{Results}

Characterization The most important product of this stage was the zoning, which was a result of integrating the Geographic Information System (GIS), georeferenced information of the five sub hydrological systems thatare found in the study area, the five types of topography and three main vegetation types present in the municipality. (Table 1). From this integration, 81 environmental units were obtained (Fig. 1), which are compatible with the scale of the work

Table 1: Zonification.

\begin{tabular}{|l|l|l|l|}
\hline Level & Enviroment & System & Key \\
\hline Criteria & \multirow{4}{*}{ Terrestrial } & Sub river basins & 3Aa \\
\cline { 3 - 4 } & & Candelaria & 6Aa \\
\cline { 3 - 4 } & & Cabo San Lucas & $6 \mathrm{Ab}$ \\
\cline { 3 - 4 } & & San José & $6 \mathrm{Ac}$ \\
\cline { 3 - 4 } & & Santiago & Ked \\
\cline { 3 - 4 } & & Las Palmas & M \\
\hline Landscape & Unity & Vegetation Type & Key \\
\hline Physiography & Key & & \\
\hline Dunes & $\mathrm{D}$ & Scrub & \\
\hline Down hills & $\mathrm{B}$ & Deciduous dry forest & S \\
\hline Valley & $\mathrm{V}$ & Forest & \\
\hline Hills & $\mathrm{L}$ & & \\
\hline Sierras & $\mathrm{S}$ & & \\
\hline
\end{tabular}
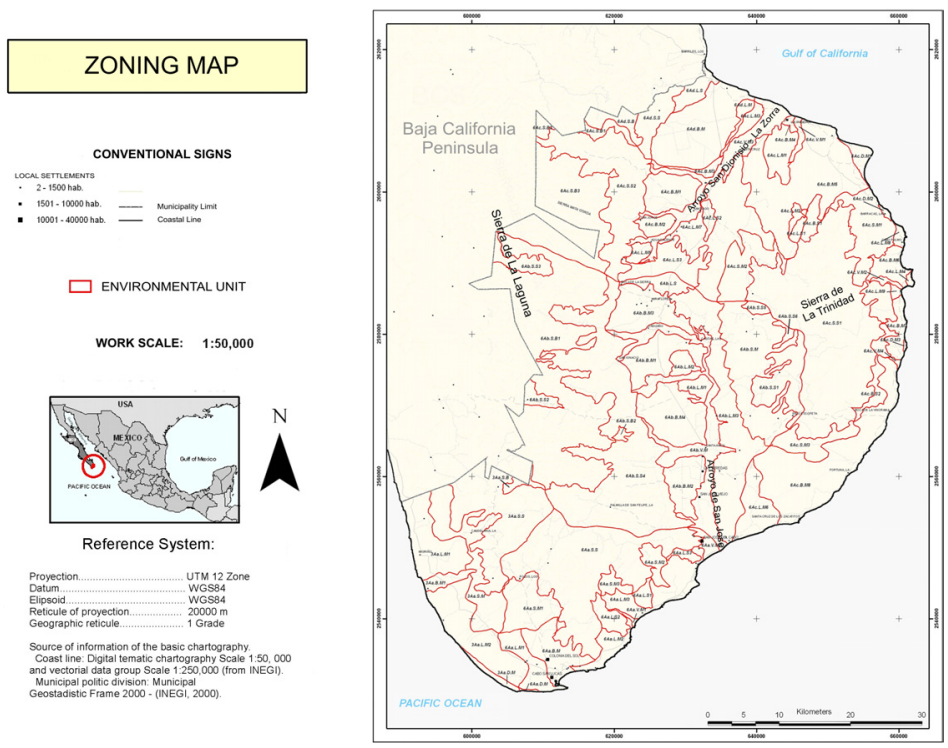

Figure 1: Zoning map. 
$(1 / 50000)$ and the initial assessment of the suitability of the land, as well as the basis for drawing up the subsequent EMU.

Diagnosis The main outcome of this phase was the analysis of suitability of land for each sector: Conservation, Tourism and Agriculture. The region is very suited to conservation ( $77 \%$ of the area has high or very high suitability), because it's associated with vulnerable coastal shrubs, lowland forest, wetlands and dunes and unique ecosystems(oak forest, pine-oak forest) that are found largely undisturbed, and species with high conservation value (endemic species and / or those at risk). In terms of the tourism industry, that focuses on traditional tourism, the suitability is greatest along the EU coast $(29 \%$ of the municipality has high or very high suitability for tourism.). For agriculture, the suitable areas are located along the two main streams and their adjacent areas, largely because of water availability and unconsolidated substrate (57\% of the municipality's surface has high or very high suitability).

Prospective Social and economic dynamics of the municipality of Los Cabos is reflected in the pressure index, which is derived from the analysis of the population, current land use and the suitability for tourism and agriculture. The areas with the highest pressure are the ones adjacent to the coast and the two main streams. The other areas have a lower rate of pressure corresponding to those units with little change of land use and less interest in the productive sectors $44 \%$ of the total area of the municipality has a high rate of development and a population growth of $9.2 \%$ per annum (INEGI [2]). Given the characteristics of the type of tourism in the area, the greatest pressure from tourism projects are located in the coastal units of the municipality, while the EU without coastline has fewer development projects. $49 \%$ of the municipality of Los Cabos has no tourism development proposals while $26 \%$ has a high concentration of projects.

The index of fragility, estimated from the index of conservation suitability [4], showed that the most vulnerable areas are the two main streams, the dunes, the Cabo Pulmo EU, and the EU system of oak and pine-oak forest

Calculations of the vulnerability index shows that $50 \%$ of the land in the municipality of Los Cabos is at a high or very high level. The EUs with a very high vulnerability are the major streams, the coastal area and the area located to the south of the Sierra de La Laguna Biosphere Reserve, which corresponds to oak forest.This defined the kind of environmental policies set for each of the Eus (Fig. 2)

Environmental policies are presented as follows: sustainable use, 15\%, preservation, $17 \%$, conservation, 68\%). In general, the strategic scenerio intended for the municipality is of conservation, which is a balance between preserving the natural environment while developing the activities of the productive sectors.

Proposal Integrating all the elements previously developed in the ecological models for the region, 23 Environmental Management Units (EMU) were composed. Each EMU is a blend of physical, biotic and socioeconomic atributes, and suitabilities. This distinguishes each of them from the rest, with the exception of the EMU for urban-tourism (18) and for the Biosphere Reserve (20) 
whose rezonificarion for the use of Soil is under the Urban Development Plan (UDP) (Anónimo [6]) and the Protected Natural Area Management Programme (CONANP [7]) respectively.
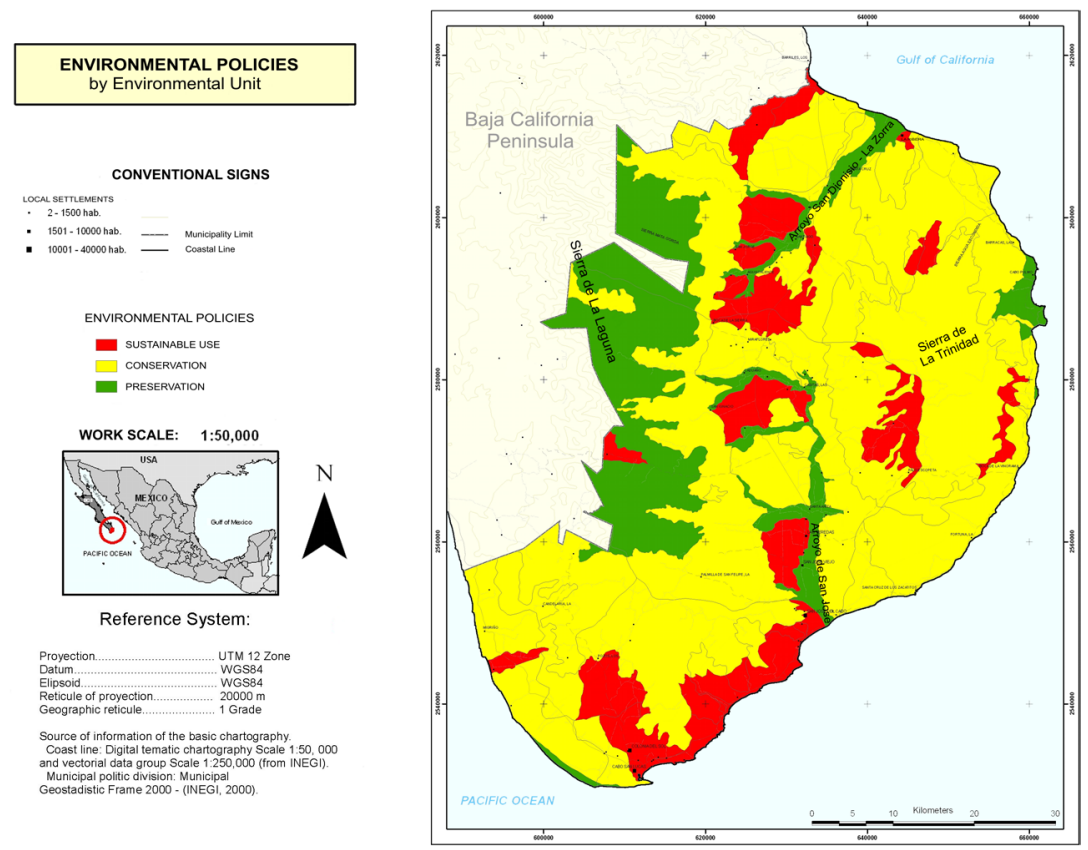

Figure 2: Environmental policies.

Each EMU was assigned one of three environmental policies (Sustainable Use, Conservation or Preservation), that further defined the guidelines reflecting the ecologically desirable state of the EMU, environmental strategies that represent the specific objectives to achieve the ecological plans and a series of specific actions that define strategies for land use for each EMU. Thus the ecological model for the region has three modes that are defined by different policies:

A) Sustainable Use Five EMUs were defined within this policy, corresponding to the EMU 18 (urban-tourism), 19, 21, 22 and 23 that cover $22 \%$ of the municipal area (Table 2). Sustainable use promotes the use and management of natural resources in an area and includes the EMU with current or potential use

Table 2: $\quad$ Environmental policies.

\begin{tabular}{|l|c|l|l|}
\hline \multirow{2}{*}{$\begin{array}{c}\text { Environmental } \\
\text { policies }\end{array}$} & \multirow{2}{*}{ EMU } & \multicolumn{2}{c|}{ Area } \\
\cline { 3 - 4 } & & Hectares & Percentage \\
\hline Preservation & 6 & 80920.66 & 21.58 \\
\hline Conservation & 12 & 211227.74 & 56.32 \\
\hline Sustainable use & 5 & 82885.00 & 22.10 \\
\hline
\end{tabular}


of resources, always respecting the fact that any use of natural resources should consider the principles of sustainability. The ecological guidelines for this policy is to develop sustainable productive activities according to the suitability of the land. The strategies developed to achieve this are: to promote the growth of sustainable farming, diversify productive activities, promote low-impact tourism activities and plan urban growth and tourism.

B) Conservation Twelve EMUs were defined for this policy, EMU 6 to 17. This policy includes $56 \%$ of the land (Table 2). This category is regarded as an intermediate environmental policy, between sustainable use and preservation, which was applied to the EMU in which productive activities or urban developments can be carried out while considering the protection of environmental services, provided by natural resources . The ecological guidelines established for this environmental policy is a balance of sustainable development and productive activities, being compatible with the conservation of natural resources. The strategies developed include the identification of natural resources and their conservation status, the study of areas suitable for the development of productive activities under a scheme of sustainability (low-impact alternative tourism, organic agriculture and cattle ranching), the implementation of techniques to reduce the impacts of productive activities on natural resources.
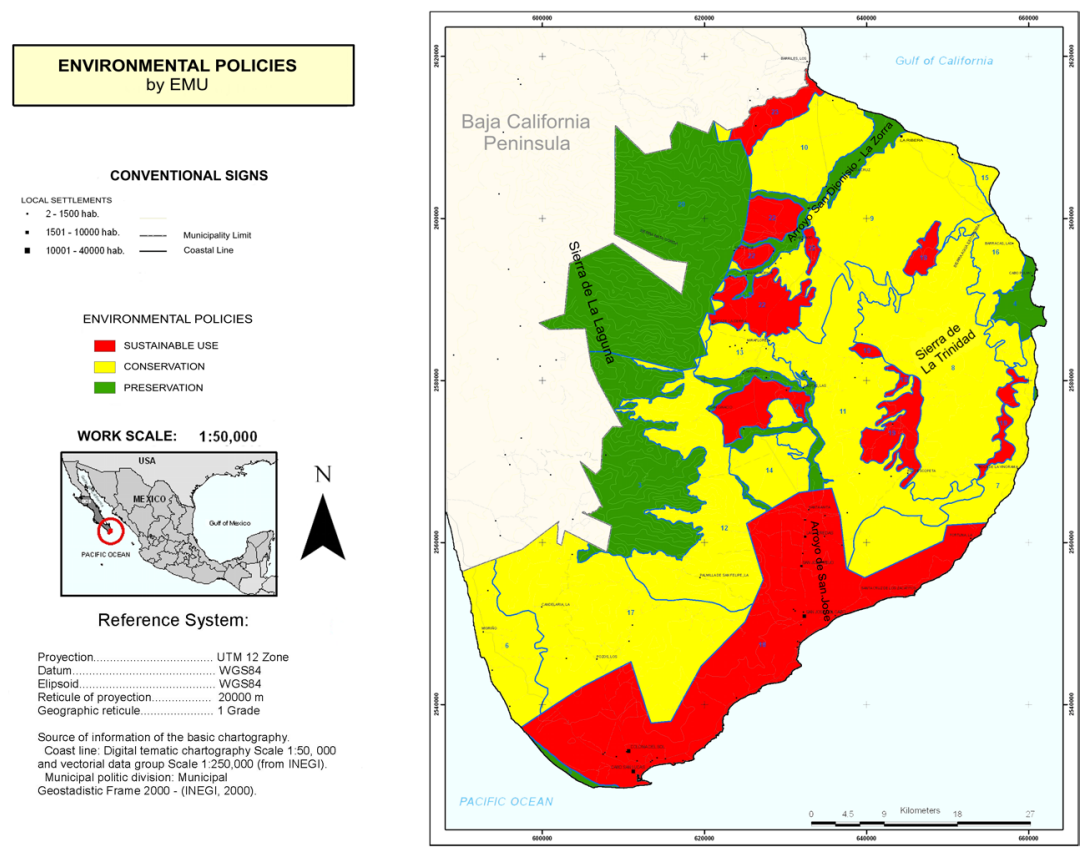

Figure 3: Environmental policies by environmental management unit.

C) Preservation For this policy six EMUs were defined, 1-5 and 20 (Fig. 3) that represent $22 \%$ of the municipality. This category was assigned to the EMUs in which it is sought to maintain the relevant characteristics of the natural 
environments. In addition, activities related to the protection of its biophysical components of the ecosystem are encouraged, while limiting productive activities andhuman settlements. The ecological guidelines defined for this policy is to protect ecosystems and ecological processes.

In summary: The municipality of Los Cabos needs to change its economic development model. The specific actions proposed for the region according to the results of the four stages are:

- The conversion of traditional farming systems into organic ones.

- $\quad$ The change from extensive ranching to a system using fenced areas and supplementary feeding.

- The development of various forms of alternative low-impact tourism.

- Rational water use.

- The research into alternative sources of water supplies for urban, agricultural and tourism use.

- $\quad$ The development of infrastructure away from residential areas at risk.

- An orderly growth of urban and suburban infrastructure outside the EMU urban-tourism.

- $\quad$ The development of low and medium intensity tourism along the coastal strip depending on the characteristics of the area.

- The relocation of existing productive activities.

- The diversification of productive activities directed towards the establishment of hunting ranches.

Furthermore, the study proposes the creation of two natural protected areas: One in the area of Cabo Pulmo-Los Frailes (EMU04) because it is a vulnerable area (according to the results of the vulnerability index) and because it is located in the zone that influences the Cabo Pulmo National Park coral reef. The second in the Sierra de la Trinidad (EMU18), is a zone of interest to the government, and represents part of the low caducifoleous rain forest of the region.

\section{References}

[1] León C., I. Espejel, L. Bravo, J. Fermán, B. Graizbord, L Sobrino, J. Sosa. El ordenamiento ecológico como instrumento de Política Pública para impulsar el Desarrollo Sustentable: Caso Noroeste de México. University of Campeche, SEMARNAT, CETYS-University of Quintana Roo. 2004.

[2] Instituto Nacional de Estadística Geografía e Informática (INEGI). Anuario Estadístico. Baja California Sur. INEGI. State Government of Baja California Sur. 485pp. 2006.

[3] Centro Estatal de Información de Baja California Sur. Programa Nacional de Turismo 2001-2006. Secretary of Tourism. México 2006.

[4] Anonymus Actualización del programa de Ordenamiento Ecológico del municipio de Los Cabos, Baja California Sur. Dirección General de Planeación, Desarrollo Urbano y Ecología. H. Ayuntamiento de Los Cabos. 246 pp. In Press. 
[5] Secretaría de Medio Ambiente y Recursos Naturales (SEMARNAT). Reglamento de la Ley General del Equilibrio Ecológico y Protección al Ambiente. Diario. Oficial de la Federación. 2003.

[6] Anónimo. 2005. Plan Municipal de Desarrollo 2005-2008. IX H. Ayuntamiento de Los Cabos, Baja California Sur. Septiembre 2005.

[7] Comisión Nacional de Áreas Naturales Protegidas (CONANP). Programa de manejo de la Reserva de Biosfera "Sierra La Laguna". CONANP. 209 pp. 2003. 